\title{
Financial and economic analysis for ground-coupled heat pumps using shallow ground heat exchangers
}

\author{
Laura Gabrielli \\ Department of Architecture, University of Ferrara, Ferrara, Italy \\ Email: laura.gabrielli@unife.it \\ Michele Bottarelli \\ Department of Architecture, University of Ferrara, Ferrara, Italy \\ Email: michele.bottarelli@unife.it
}

\begin{abstract}
A discounted cash flow analysis (DCFA) and a cost benefit analysis (CBA) have been implemented in order to investigate the economic aspects of ground-coupled heat pump (GCHP) for space heating and cooling, in comparison to traditional condensing boiler (CB). The DCFA allows the analysis of investment costs, operating costs and savings of the two different systems in order to understand if the GCHP's pay back periods (PBPs) is more interesting than that of CB in coming years. The first financial model (DCFA) takes account for economic factors as prices, costs and growth, while the economic approach (CBA) include the carbon price into the calculation, considering the social costs of carbon dioxide emissions.

The whole analysis is implemented adopting a parametric approach, in which all the economic terms are linked to energy labels, degree-days and energy mix ratios (EMRs), the latter obtained as ratio between the cost of electricity and natural gas paid by the householder. Relating to different EMRs, the PBPs are presented in matrixes in which energy labels and degree-days are the row/column indexes, to confront the benefits of choosing between GCHP versus CB. The PBPs are also calculated with the introduction of the carbon price, so that some considerations about the environmental aspects are presented. The results show that all higher energy labels have a good profitability ratio between costs and payback periods and demonstrate that GCHP system does pay off.
\end{abstract}

Keywords: Discounted cash flow analysis; Payback periods; Ground-coupled heat pump; Energy efficiency; Decision support matrixes; Cost - benefit analysis.

\section{Introduction}

Buildings are estimated to be responsible for a very high percentage of energy consumption and gas emissions. This implies a growing attention within the construction and real estate sectors regarding the buildings role in exploiting renewable energy and in reducing climate change. Despite the rapid grow of green buildings supply, few works investigate the influence on financial premium of energy saving, environment design and efficient technologies, i.e. in [1].

Here, an economic analysis is carried out to evaluate the payoff for ground-coupled heat pump system (GCHP) for space heating, in comparison to traditional condensing boiler (CB); the cooling mode has been considered only as installation extra-cost for the case $\mathrm{CB}$, without taking into account the energy consumption. The two different technologies are supposed working in the same indoor system installation, so only the machines and the additional accessories are considered. The 
behaviour of the supposed geothermal closed loop is numerically solved in a preliminary work [2], taking into account different classes of degree-days and thermal insulations. In the present study, the cited work is detailed and partially revised to support a new economic framework in terms of energy requirements, according to climate zones and building thermal transmittances.

In our case study, in the discounted cash flow analysis (DCFA), investment and operating costs and revenues of the two different systems are calculated in order to understand if the GCHP outperform its counterpart. The whole analysis was performed adopting a parametric approach, in which all the previous terms are linked to energy label, degree-days and energy mix ratios (EMRs), the latter obtained as ratio between the full unit cost of natural gas and electrical energy paid by the consumer. The DCFA has been then integrated with external costs in order to obtain a cost benefit analysis (CBA). CBA is not limited to monetary considerations only, but it often includes environmental and social costs/benefits that can be quantified with a direct or indirect method. In our case study, the CBA attaches monetary value to carbon dioxide emissions reductions and brings it into energy-related investment decisions.

The paper seeks to analyse first the economic aspects of traditional CB versus GCHP, in order to examine the benefits of choosing between the different systems. Secondly, the work focuses on $\mathrm{CBA}$ and some results are presented in order to express the environmental aspects.

\section{Methodology}

The aim of this paper is to calculate the payback period (PBP) of a GCHP versus a CB, in connection with degree-days and energy building labels, expanding the methodology reported in [2] to consider both the winter and summer seasons. The whole energetic analysis here employed is got from [2] and [3], to which we refer for more detailed information than those reported below. Unlike the thermo-physical approach, more advance financial study is performed and some specific considerations are included in this model. In particular, the cash flow of costs and savings has been discounted using a weighted cost of capital (WACC), which reflects the average benchmark parameters and drivers (cost of capitals) for the energy sector. Moreover, the analysis explicitly takes into account the time-series pattern of energy costs that are used, in the model, to forecast the evolution of electricity costs and natural gas costs in the future. Lastly, a CBA has been performed which includes the carbon price in the model, taking account the monetary value to carbon dioxide emissions reductions.

The energetic analysis in [2] links the building energy requirements for air-conditioning to climate aspects and energy labels taken from the Italian regulation that origins as adoption from European directive. However, they can be easy extended to any other country setting different degree-days and energy requirements. The climate conditions are generated from a parameterized hourly time series air temperature, through which specific degree-days are obtained. Because both air-conditioning systems are supposed working at fixed low temperature $\left(44^{\circ} \mathrm{C}\right.$, radiant floor), the indoor distribution plant is avoid from the study in terms of installations and operations costs. The GCHP is a HP vapour compression type coupled to a shallow ground heat exchanger (GHE), while the $\mathrm{CB}$ is a boiler with high performance.

The coefficient of performance (COP) of the GCHP basically depends on the temperature at the evaporator, if the temperature at the condenser is considered fixed, owing to the indoor heating plant temperature. Moreover, the evaporator temperature is depending on the climate and the 
thermal behaviour of the GHE and surrounding soil, so that this last coupling is considered as a key factor to a correct approach of the problem.

The GHE's heat exchange is solved implementing a numerical model in unsteady state, as reported in [3]. Moving from a benchmark case of degree-days, the energy supply is calibrated to maintain an average temperature not lower than $0^{\circ} \mathrm{C}$ in the ground surrounding the exchanger, in order to exclude the usage of glycol. The combination between degree-days and power trend for exchanger unit length represents the limit that every other combination must respect. So, all the other cases are gathered as different combinations among climate zones and energy requirements.

The thermal analysis has generated all the data for the following economic valuations, where installation and operation costs are considered to achieve a full price for unit building volume. The economic analysis is performed adopting different ratio between the full unit cost of natural gas and electricity, and their potential growth, in order to connect the payback and pay off to an energy mix ratio (EMR). In the following sections, the former steps are reported to explain the approach of the research.

\subsection{Building energy requirements}

The building is here simplified as a closed thermodynamic system, characterized by lumped parameters, as proposed in [2]. The lumped parameters control the heat transfer through its envelope, according to the different air temperature between outdoor and indoor, and the overall thermal transmittance. This last one is related to the Italian regulation, which acknowledges the European directive on energy savings. Indeed, the regulation defines the building energy labels $\left(a^{+}, a, b, c, d, e, f, g\right)$, according to the maximum energy requirements for space heating of building's unit volume $\left(E P_{i}\right)$ in seven climate zones $(A, B, C, D, E, F)$ defined by degree-days $(D D)$, and the building shape ratio $(S / V)$. Thus, in [2] is introduced the overall equivalent transmittance $\hat{U}$, as follows:

$$
\widehat{U}=\frac{k \cdot E P_{i}}{\frac{S}{V} \cdot D D \cdot t}
$$

where the $k$ factor is setting the energy requirement of the specific energy label, and $t$ the daily operation time expressed in hour if $E P_{i}$ is given in $\mathrm{kWh} / \mathrm{m}^{3}$ per heating season. In Tab.1 are reported the five selected $k$ factors; each factor represents the mid-value of the corresponding energy class $(a, b, c, d, e)$, whom range is fixed by the Italian regulation.

To generalize the climate zones through the degree-days $(D D)$, a time series for the outdoor air temperature has been conceptualised as hourly sinusoidal trend, superimposed between the daily maximum and minimum variation of the seasonal temperature. The method is broadly presented in [3] and employed in [2] and [4]. As consequence, the overall equivalent transmittance only becomes related to climate zones and energy label. As reported in [2], for the given boundary conditions of Tab.1 and Tab.2, the resulting overall equivalent transmittance coefficient is depicted in Tab.3, where the best and the two worst energy labels $\left(a^{+}, f, g\right)$, and the climate zones $A$ are omitted due to their extreme values. Expressly for the daily operation time, the reported values are the average of the overall operating hours of the air-conditioning plant, as become from the same fixed daily scheduling for all different climate zones. 
Table 1: $\boldsymbol{k}$ factor for the selected energy labels

Table 2: Data for selected climate zones (heating mode)

\begin{tabular}{ccccccc}
\hline Data & Unit & $B$ & $C$ & $D$ & $E$ & $F$ \\
\hline Daily operation time & hours/day & 7.2 & 8.0 & 9.0 & 9.6 & 10.5 \\
Heating Degree-Days & $\mathrm{DD}$ & 750 & 1150 & 1750 & 2550 & 3550 \\
$\mathrm{EP}_{\mathrm{i}}$ & $\mathrm{kWh}_{\mathrm{t}} / \mathrm{m}^{3}$ year & 8.1 & 11.2 & 15.4 & 20.4 & 22.9 \\
\hline
\end{tabular}

Table 3: Overall equivalent transmittance coefficient, $\mathrm{W} / \mathrm{m}^{2} \mathrm{~K}$

\begin{tabular}{cccccc}
\hline & $B$ & $C$ & $D$ & $E$ & $F$ \\
\hline$a$ & 0.95 & 0.82 & 0.71 & 0.60 & 0.44 \\
$b$ & 1.61 & 1.40 & 1.20 & 1.02 & 0.75 \\
$c$ & 2.25 & 1.95 & 1.68 & 1.42 & 1.04 \\
$d$ & 2.89 & 2.51 & 2.16 & 1.83 & 1.34 \\
$e$ & 3.83 & 3.33 & 2.87 & 2.43 & 1.78 \\
\hline
\end{tabular}

Assuming the hypothesis of closed thermo-dynamical system, the building only can exchange heat with the ambient, which is related to the variation of its internal energy. This last one can be calculated by the variation of the average temperature of its global mass, according to its specific heat. The building global mass may be expressed only from walls, roof and foundation, because the air contribute is negligible. Fixing the building volume $(V)$, the average density $(\rho)$ and specific heat (c) of the plenum, and the ratio $(r)$ between plenum over building volume, the variation of the internal energy should be related only to the heat transfer through its envelope, and thus:

$$
r \cdot V \cdot \rho c \cdot d T=-\widehat{U} \cdot S \cdot\left(T-T^{a i r}\right) \cdot d t
$$

Because the outdoor air temperature variation is independent from the building behaviour, the previous Eq.(2) may be integrated in time, as follows:

$$
T(t)=T^{a i r}+\left(T_{0}-T^{a i r}\right) \cdot e^{-\frac{S}{V} \cdot \frac{\hat{U} \cdot\left(t-t_{0}\right)}{r \cdot \rho c}}
$$

where $T_{0}$ is the indoor air temperature at time step $t_{0}$, when the plant is switched off. Starting from this off-time, the indoor temperature $T$ changes according to the overall transmittance $\hat{U}$ and the outdoor temperature $T^{\text {air }}$. When switched on, the indoor temperature $T$ is fixed to a target value set for heating and cooling mode $\left(T^{h / c}\right)$. For simplicity, we assumed that the plant is able to reach the target temperature in a single time step set equal to one hour. The target temperature has been taken equal to $20^{\circ} \mathrm{C}$ in winter and $24^{\circ} \mathrm{C}$ in summer. Low temperature in summertime has been assumed to simplify a higher requirement related to the latent heat of humidity condensation.

As consequence, the energy requirement per unit volume $(q)$ is related only to the outdoor air temperature, as solved in Eq.4:

$$
q(t)=r \rho c \cdot\left(T^{h / c}-T_{0}\right)+\widehat{U} \frac{S}{V} \cdot\left(T^{h / c}-T_{a i r}\right) \cdot \Delta t
$$


where $\Delta t$ is the time step, assumed equal to one hour for the present analysis. The first and second term of Eq.(4) account respectively for the energy needed to reach the target temperature from the initial value when the plant is turned on, and that required to maintain it due to the heat transfer occurring through the envelopment. After the first time step, the indoor temperature is supposed to have reached the target temperature and the first term in the Eq.(4) becomes null. Each other gain, such as solar radiation, internal heat gains and so on, is here neglected for simplicity reasons. In Tab.4, the building parameters and the target temperatures employed are reported.

Table 4: Building parameters

\begin{tabular}{crcl}
\hline Parameter & Value & Unit & \multicolumn{1}{c}{ Description } \\
\hline$S / V$ & 0.5 & - & Building shape ratio \\
$\rho$ & 1,000 & $\mathrm{~kg} \mathrm{~m}^{-3}$ & Wall density \\
$c$ & 900 & $\mathrm{~kJ} \mathrm{~kg}^{-1} \mathrm{~K}^{-1}$ & Wall specific heat \\
$r$ & 0.1 & - & Ratio between plenum and overall building volume \\
$T^{h}$ & 20 & ${ }^{\circ} \mathrm{C}$ & Indoor target temperature in heating mode \\
$T^{c}$ & 24 & ${ }^{\circ} \mathrm{C}$ & Indoor target temperature in cooling mode \\
\hline
\end{tabular}

\subsection{Parametrization of the heat pump operating mode}

According to the previous considerations, the minimum fluid temperature leaving the indoor circulating pump is set in heating mode to $44^{\circ} \mathrm{C}$, and the temperature at the heat pump condenser may be supposed only few degrees higher $\left(46^{\circ} \mathrm{C}\right)$, in order to perform suitably the heat exchange during condensation process. Neglecting superheating/undercooling conditions and considering irreversibility coefficients to take into account the real processes, the thermodynamic cycle only depends from the temperature at the evaporator. However, the temperature at the evaporator is linked to the GHE, and therefore the COP is only related to the fluid temperature leaving the GHE. We limit the temperature of the working fluid in the range $0-30^{\circ} \mathrm{C}$ to exclude icing (heating mode, no glycol) and environmental effects (cooling mode, vegetation).

If we adopt the refrigerant R134a, the thermodynamic cycle operates in the Pressure-Enthalpy chart, where the relationships between enthalpy and temperature of the working fluid are easy to estimate. According to the Fig.3 and [5], in [2] the most important functions were estimated in heating mode, for the working temperature supposed at the condenser $\left(46^{\circ} \mathrm{C}\right)$, whose saturated pressure is $1.20 \mathrm{MPa}$. The specific relations of enthalpy-temperature are reported in Tab.5 and hold very high variances $\left(\mathrm{R}^{2}>0.96\right)$. The specific work performed by the compressor is defined by the adiabatic $\underline{12}$, and corrected by means of an irreversibility coefficient $\eta_{12}$. The heat transfer at the condenser, that represents the energy requirement of Eq.4, is calculated with regard to the enthalpies $h_{2}$ and $h_{3}$, and adopting a heat transfer coefficient $\eta_{23}$. Both compressor and condenser performances are taken equal to 0.85 .

Table 5: Relationships in temperature at the evaporator in heating mode $(R 134 a)$

\begin{tabular}{ccc}
\hline Quantity & Relationships, adopting T in ${ }^{\circ} \mathrm{C}$ & Unit \\
\hline$h_{1}$ & $-0.0013 \cdot T^{2}+0.5774 \cdot T+397.3$ & $\mathrm{~kJ} / \mathrm{kg}$ \\
$h_{2}$ & $0.0012 \cdot T^{2}-0.1988 \cdot T+426.2$ & $\mathrm{~kJ} / \mathrm{kg}$ \\
$h_{3}, h_{4}$ & 265.6 & $\mathrm{~kJ} / \mathrm{kg}$ \\
$l_{12}$ & $0.0025 \cdot T^{2}-0.7762 \cdot T+28.9$ & $\mathrm{~kJ} / \mathrm{kg}$ \\
$q_{23}$ & $0.0012 \cdot T^{2}-0.1988 \cdot T+160.6$ & $\mathrm{~kJ} / \mathrm{kg}$ \\
\hline
\end{tabular}




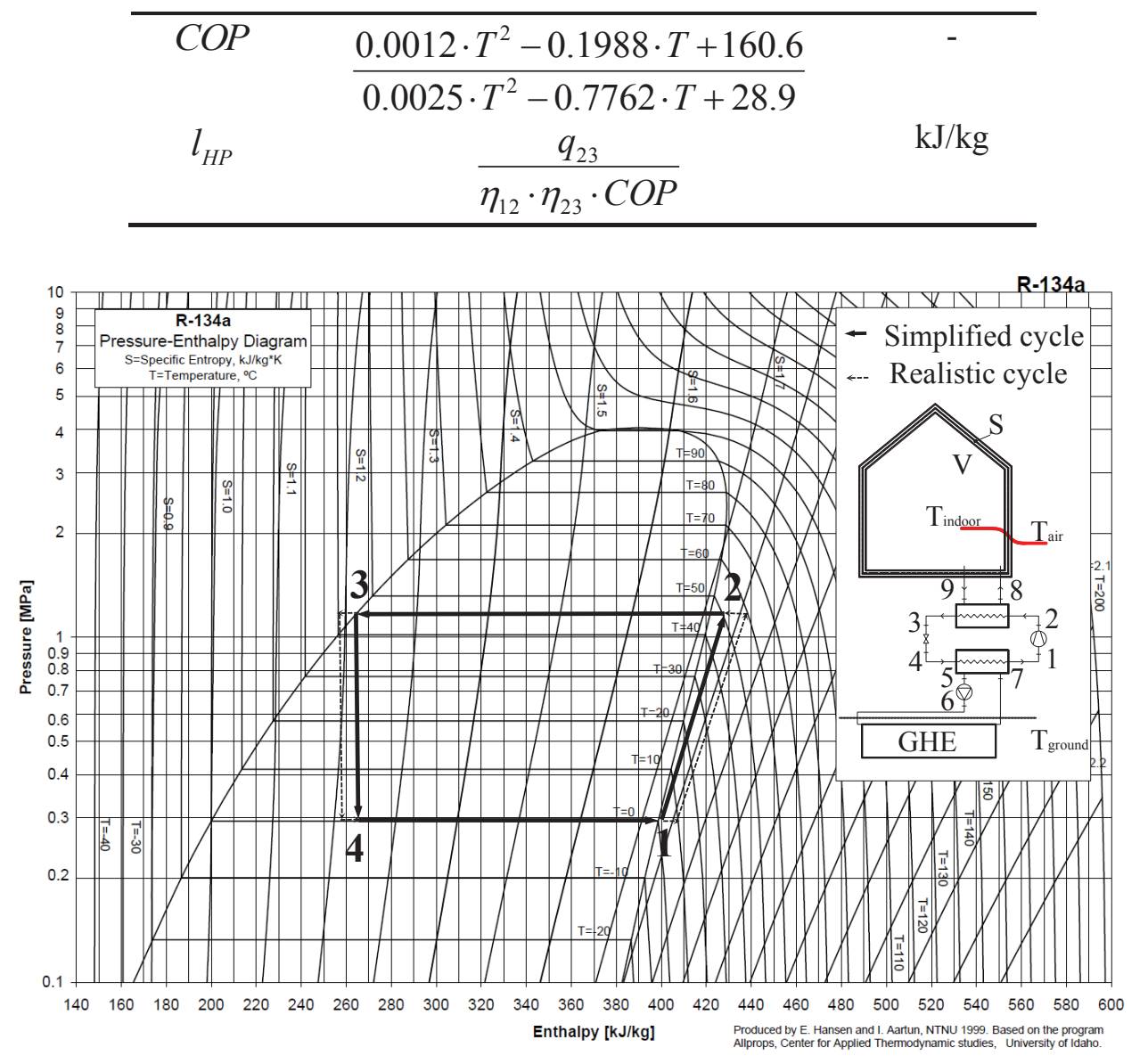

Figure 1: R134a thermodynamic diagram and simplified cycle in heating mode

\section{Geothermal closed loop}

The evaluation of the GHE performance was assumed as reported in [2-4], to which we refer and remand for more details. In [3] and [4] the solution of a single benchmark case was carried out by means of an unsteady-state 3D numerical finite element model. The benchmark case was set to bring the behaviour of the system up to $0^{\circ} \mathrm{C}$ of the GHE leaving water for given building energy requirement, and thus for fixed time series of the outdoor air-temperature. Therefore, the supposed GHE length was representative of a limit case, and each other case would have been proportionally related to this, according different energy requirement.

The model was implemented in a commercial software $\left(\mathrm{FEFLOW}^{\circledR}\right)$, which solves the analysis of flow and heat transfer in saturated/unsaturated porous media, considering both conductive and convective heat transport. The GHE used herein was a flat-panel $0.80 \mathrm{~m}$ high, $0.02 \mathrm{~m}$ wide and 5.0 $\mathrm{m}$ long, buried edgeways in a trench $6.0 \mathrm{~m}$ long, $0.30 \mathrm{~m}$ wide and $2.49 \mathrm{~m}$ deep. The overall computational domain was subdivided into 23 horizontal layers (Fig.2) and the groundwater flow was imposed parallel to the GHE direction with a piezometric gradient of $0.2 \%$. The hydraulic and thermal properties attributed to the different domain components (fluid within the panel, backfill, and surrounding soil) were assumed homogeneous and typical for water, bentonitic clay and sandy silts, within the ranges usually cited in [3]. Here, thermal boundary conditions were given at the soil surface in form of temperature time series, applying a coefficient at the previous sinusoidal function for air temperature, set equal to 0.6 .

The GCHP operation hours were selected to represent frequent working conditions, 5-9 am and 5-10 pm from Monday to Friday, 7-11 pm on weekends. The heating operation was allowed from 
October $15^{\text {th }}$ to April $30^{\text {th }}$, the cooling from June $1^{\text {st }}$ to September $30^{\text {th }}$. During this time, the HP was activated in heating/cooling mode to maintain the indoor target temperature $\left(20 / 24^{\circ} \mathrm{C}\right)$, supplying the heat estimated according to Eq.(4) for each time step. For simplicity, it was assumed that this heat and the related power is the same requested at the GHE, and the compressor works only to raise it at the target temperature, overrating the energy required from the GHE. The flow rate into the GHE was calculated to have water with $3^{\circ} \mathrm{C}$ between the inlet and outlet temperature $\left(\Delta T_{67}\right)$, by means of a specific numerical loop supplied directly from the FEFLOW's developers [6].

The resulting temperatures for the benchmark case are showed in Fig.3.

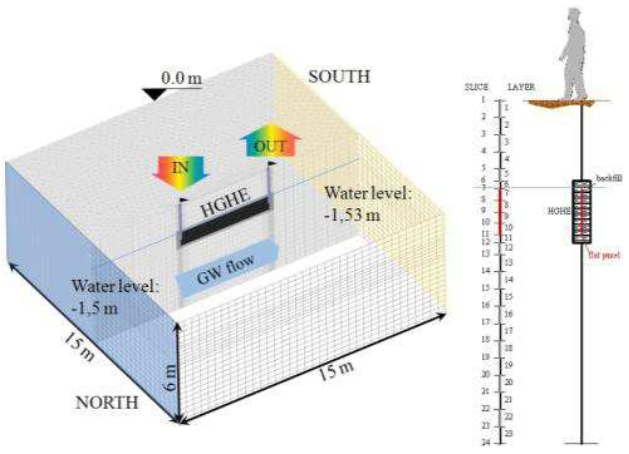

Figure 2: Computational finite elements domain of the benchmark case

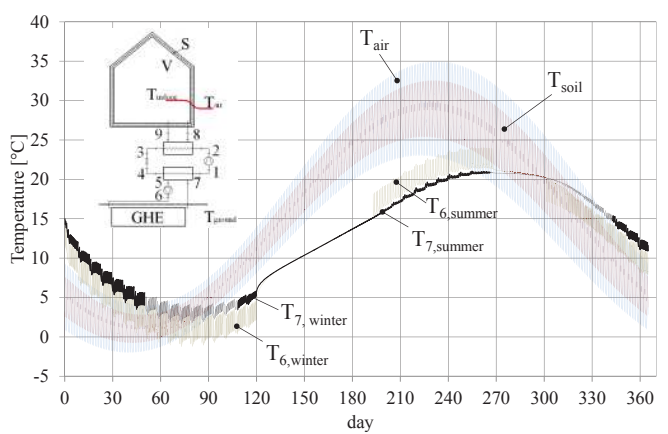

Figure 3: Time series for the resulting temperatures of the benchmark case

The minimum temperature at the GHE surrounding soil reaches $0^{\circ} \mathrm{C}$ at $70^{\text {th }}$ day; no lower temperature is acceptable without freezing problem. It means that no higher heat transfer is possible for this configuration, according to initial soil temperature, degree-days, energy requirements and GHE type and length. The maximum power is $36 \mathrm{~W} / \mathrm{m}$ in heating mode for each meter of GHE; the average is $27 \mathrm{~W} / \mathrm{m}$. The soil volume surrounding the GHE, whose temperature varies more than $0.5^{\circ} \mathrm{C}$ from initial condition, is almost $80 \mathrm{~m}^{3}$.

Since the run for a full year needed a very long computational time, each case was examined according to the previous limit, and assuming the following hypothesis and observations between the limit case $L$ and each other new case $N$ :

- the maximum soil thermal exploitation is related to the initial average temperature in the involved ground volume $\left(\bar{T}_{i}^{S}\right)$, and the heating time period $(\Delta t)$;

- the difference of the initial soil temperatures between two cases $\left(\bar{T}_{i, N}^{S}-\bar{T}_{i, L}^{S}\right)$ is equal to the difference of their yearly average air temperatures $\left(\bar{T}_{N}^{a i r}-\bar{T}_{L}^{a i r}\right)$, because the related sinusoidal functions are in phase;

- the GHE water leaving temperature for each new case $N$ can be obtained by the numerical solution resulting from the limit case $L$, in accord to the difference between the two initial soil temperatures, and the heating time period;

- the major or minor heat power for different case requires a proportional GHE length to give similar energy behaviour for unit length of limit case $L$;

- the difference energy balance on soil surface between two cases is neglected.

Therefore, the energy balance for each new case $N$ must be equal to that of the limit case $L$ : 


$$
c_{S} \rho_{S} V_{S} \cdot\left(\bar{T}_{i, N}^{S}-\bar{T}_{f, N}^{S}\right)+c_{w} \rho_{w} \dot{V}_{N}^{w} \Delta T_{67} \Delta t_{N}=c_{S} \rho_{S} V_{S} \cdot\left(\bar{T}_{i, L}^{S}-\bar{T}_{f, L}^{S}\right)+c_{w} \rho_{w} \dot{V}_{L}^{w} \Delta T_{67} \Delta t_{L}
$$

where $c_{s}$ and $\rho_{s}$ are the soil specific heat and density, $V_{s}$ the soil volume involved by the heat transfer problem, $c_{w}$ and $\rho_{w}$ the specific heat and the density of the working fluid (water), $\dot{V}_{N}^{w}, \Delta t_{N}$ and $\dot{V}_{L}^{w}, \Delta t_{L}$ the average volumetric flow rate of the working fluid and the heating period for the cases $N$ (new) and $L$ (limit), and $\Delta T_{67}$ the difference of temperature at the evaporator/condenser fixed to $3^{\circ} \mathrm{C}$.

Since their final average temperatures must be the same $\left(\bar{T}_{f, N}^{S} \equiv \bar{T}_{f, L}^{S}\right)$ and heating period is assumed identical $\left(\Delta t_{L} \equiv \Delta t_{N}\right)$, the new flow rate at the GHE becomes:

$$
\dot{V}_{N}^{w}=\dot{V}_{L}^{w}+\frac{c_{s} \rho_{s} V_{s}}{c_{w} \rho_{w} \Delta T_{67} \Delta t_{L}} \cdot\left(\bar{T}_{N}^{\text {air }}-\bar{T}_{L}^{\text {air }}\right)
$$

and the new GHE water leaving temperature is represented by the following proportion:

$$
T_{N}(t)=T_{L}(t)-\left(\bar{T}_{N}^{a i r}-\bar{T}_{L}^{a i r}\right) \cdot\left(1-\frac{t}{\Delta t_{L}}\right)
$$

\section{$4 \quad$ Discounted cash flow analysis}

The Discounted cash flow analysis has been extensively used in real estate and construction sector [7], [8]. The economic analysis was undertaken using the discounted cash flow approach in order to compare the different scenarios. The key inputs for the DCFA approach are:

- the cost of investment for both CB and GCHP;

- future cash inflows or outflows as the costs of maintenance and the energy costs;

- the amount of increase of energy costs (growth rate);

- the discounted rate: the discount rate should be equal to the required rate of return for the investment project, and should take into account the price inflation, the project risk and the real required return;

- the number of years (n) over which it is possible to estimate project profitability.

Once that all inputs are modelled, the investment feasibility calculations are carried out and all the present and future inflows and outflows are discounted to obtain different outputs as the net present value (NPV), the internal rate of return (IRR) or the payback period (PBP).

The NPV represents the present value of all incomes and costs during the period of analysis of the project. Where the NPV gives us a number larger than zero, the project can be accepted. If the NPV is negative, the project must be rejected or, at least, modified. The IRR is the discount rate that makes the NPV of all cash flows (both positive and negative) equal to zero, so when the NPV of all costs equals the NPV of all incomes or revenues of the project. The IRR evaluates the desirability of investments or projects so the higher a project's internal rate of return, the more desirable it is to undertake the project. Usually the IRR must exceed the cost of capital or a minimum acceptable rate of return. IRR is an indicator of the efficiency, quality, or yield of an investment, while the NPV is an indicator of the value of an investment. 
The PBP for a project is the time in which the initial cash outflow (usually the cost of investment) is expected to be recovered from the cash inflows generated by the project. The cash flows are added up after taking account of the time value of money. The decision is based on comparing the different pay back periods with a predetermined cut off period decided by the decision maker, as considered also in [9].

In our analysis, we considered the PBP in order to verify if the GCHP pays off in comparison with the $\mathrm{CB}$. To undertake the economic analysis, it needs to identify all the critical inputs and assign appropriate values to them based on an analysis of the current market and experiences. The payback period was calculated based on the investment (initial) cost difference between the GCHP and the $\mathrm{CB}$, and the annual energy and maintenance savings, which is possible to obtain using a GCHP instead of CB. As savings are considered like revenues for a household, the approach is a DCFA rather than a Life Cycle Cost, which includes only costs in the analysis [10].

The economic inputs used in the model are listed in Tab.6.

Table 6: The economic inputs

\begin{tabular}{|c|c|c|c|c|c|c|c|c|c|}
\hline Description & Value & Units & Life cycle & Scenarios & 1 & 2 & 3 & 4 & Units \\
\hline Indoor circulating pump & 3.000 & $€ / \mathrm{We}$ & 10 years & NATURAL GAS & 1.260 & 0.840 & 0.683 & 0.525 & $€ / \mathrm{Nm} 3$ \\
\hline GCHP & 0.230 & $€ / \mathrm{We}$ & 15 years & ELECTRICITY & 0.240 & 0.200 & 0.195 & 0.175 & $€ / \mathrm{kWh}$ e \\
\hline Stack & 0.120 & $€ / W t$ & - & EMR & 0.190 & 0.238 & 0.286 & 0.333 & kWh_e/Nm3 \\
\hline $\mathrm{CB}$ cost of maintenance & 0.120 & $€ / \mathrm{m}^{3}$ & 1 year & GROWTH ELECTRICITY ( ge ) & $3.1 \%$ & $3.1 \%$ & $3.1 \%$ & $3.1 \%$ & $\%$ \\
\hline GSHP cost of maintenance & 0.011 & $€ / \mathrm{m}^{3}$ & - & GROWTH GAS ( gs ) & $2.9 \%$ & $2.9 \%$ & $2.9 \%$ & $2.9 \%$ & $\%$ \\
\hline Pollution check & 0.300 & $€ / \mathrm{m}^{3}$ & 1 year & Carbon footprint (Electricity) & 112 & 225 & 318 & 397 & gCO2-eq/kWh_e \\
\hline Major use of power & 0.005 & $€ / \mathrm{We}$ & 1 year & Carbon footprint (Gas) & 2500 & 2500 & 2500 & 2500 & $\mathrm{gCO} 2-\mathrm{eq} / \mathrm{kWh} \mathrm{t}$ \\
\hline GHE & 40.000 & $€ / \mathrm{m}$ & 30 years & Carbon Price & 40.00 & 40.00 & 40.00 & 40.00 & $€ /$ Tonne $\mathrm{CO} 2$ \\
\hline HVAC & 0.350 & $€ / \mathrm{Wt}$ & 15 years & & & & & & \\
\hline
\end{tabular}

The analysis had been performed in nominal terms, so both the cash flows and the discount rate are in nominal terms. The cost of investment $\mathrm{Ci}$ is calculated as follows:

$$
C_{i}=C_{0}+\sum_{t=0}^{n} C_{0}\left[\left(\frac{r}{(1+r)^{t}-1}\right) \cdot \frac{1}{(1+r)^{t}}\right]
$$

in which $\mathrm{C}_{0}$ is the instalment cost and the sinking funds formula has been used to build up a sum of money to replace the systems after their usable life. The annuity payment has been then discounted in order to sum it up to the cost of instalment. The formula for the sinking funds is:

$$
a=C_{0} \frac{r}{(1+r)^{t}-1}
$$

where a is the annuity payment. The final value is used to replace the equipment at the cost $\mathrm{C}_{0}$ some point in time, defined according the different life cycles of the equipment. Some minimum cost of investment were introduced in order to reflect the presence of some instalments which are indivisible and that remain constant for low level of production (e.g. small volumes, small houses, etc.). All instalment costs were extrapolated from price lists for geothermal heat pumps, as well as maintenance costs. Price for natural gas and electricity were taken from a dwelling's average energy bill. 
All operating costs were included in the model as indicated in tab. 6, considering a growth rate of energy. This growth rate have been set using time series data (prices/semi-annual) to forecast future price evolution. In order to estimate the growth rate, a backward - looking price behaviour analysis has been carried out. Collecting data of electricity price and natural gas prices from the last 10 years in the European zone [11], a simple Ordinary Least Squares regression (simple OLS) for natural gas prices and electricity prices has been used, which takes the following form:

$$
\mathrm{Yi}=\beta_{0}+\beta_{1} \mathrm{X}_{1}+\varepsilon
$$

with $\mathrm{n}$ observations $\mathrm{i}$ measured by dependent variable $\mathrm{Yi}$ and independent variable $\mathrm{Xi}$, and two parameters describing a line, a vertical intercept term $\beta_{0}$ and slope term $\beta_{1}$ and an error term $\varepsilon i$ that represents the error or difference between the actual observation value yi and the value yi predicted by the regression. This approach follows the classical line of price prediction in international electricity and natural gas markets where the main idea is to use historical data, e.g., past prices, load, and supply, for training a price model for the following periods. The two OLSs shows (Fig.4 and 5) different price patterns: the natural gas prices have fluctuated in recent years, so the linear regression model is so limited in demonstrating the trends that have occurred in the past $\left(\mathrm{R}^{2}=0.54\right)$. In contrast, the evolution of electricity prices is well represented by the linear regression $\left(\mathrm{R}^{2}=0.94\right)$. The rates were extrapolated which gives us a yearly growth rate of electricity of $3.1 \%$ and $2.9 \%$ rate for natural gas, on average.

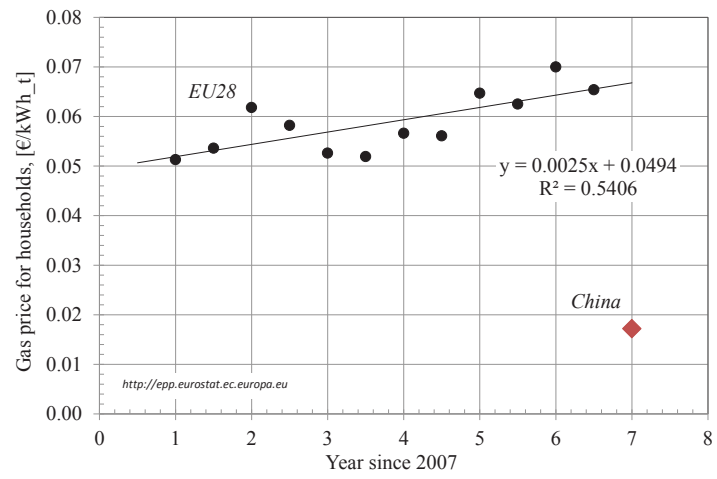

Figure 4: OLS for Natural Gas Prices

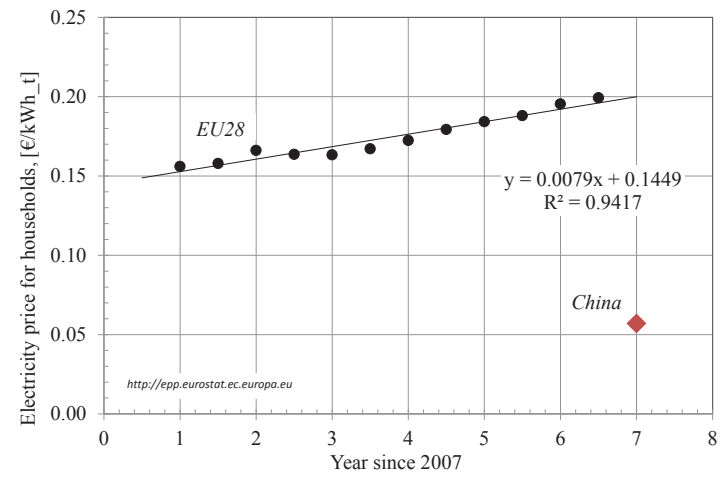

Figure 5: OLS for Electricity Prices

The operating cost of $\mathrm{CB}$ and GCHP (maintenance and energy costs) are calculated as follows:

$$
C e=\sum_{t=0}^{n} C_{E}\left[\left(\frac{(1+g)^{t}}{(1+r)^{t}}\right)\right]
$$

In Eq. (11) Ce are the operating costs, $g$ is the growth rate; $r$ is the discount rate, as reported in [12]. The payback period is finally calculated as:

$$
P B P: \frac{C i_{G C H P}-C i_{C B}}{C e_{C B}-C e_{G C H P}}
$$


or, alternatively:

$$
P B P: \frac{C_{0 G C H P}+\sum_{t=0}^{n} C_{0}\left[\left(\frac{r}{q^{t}-1}\right) \cdot \frac{1}{q^{t}}\right]-C_{0}+\sum_{t=0}^{n} C_{0 C B}\left[\left(\frac{r}{q^{t}-1}\right) \cdot \frac{1}{q^{t}}\right]}{\sum_{t=0}^{n} C_{E C B}\left[\left(\frac{(1+g)^{t}}{q^{t}}\right)\right]-\sum_{t=0}^{n} C_{E G C H P}\left[\left(\frac{(1+g)^{t}}{q^{t}}\right)\right]}
$$

where $q=1+r$ and:

- $\mathrm{C}_{0 \mathrm{GCHP}}$ : cost of investment for GCHP system

- $\mathrm{C}_{0 \mathrm{CB}}$ : cost of investment for CB system

- Ce $\mathrm{GCHP}_{\mathrm{GC}}$ operating costs (maintenance and electricity costs) for GCHP system

- $\mathrm{Ce}_{\mathrm{CB}}$ : operating costs (maintenance and natural gas costs) for $\mathrm{CB}$ system

The weighted average cost of capital (WACC) has been used for deriving the discount rate for determining the present value of the cash flows. The WACC approach is commonly used as the discount rate reflects the fact that projects are normally funded by both debt and equity. The WACC equation is the cost of each capital component multiplied by its proportional weight and then summing:

$$
W A C C=K_{d} \frac{D}{D+E}+K_{e} \frac{E}{D+E}
$$

where:

$-\mathrm{K}_{\mathrm{e}}=$ cost of equity

$-\mathrm{K}_{\mathrm{d}}=$ cost of debt

- $\mathrm{E}=$ market value of the investor's equity

- $\mathrm{D}=$ market value of the investor's debt

- $E=$ percentage of financing that is equity

- $\mathrm{D}=$ percentage of financing that is debt

To discount the future cash flows a financial structure (Debt/Equity ratio) of 0.60/0.40 was considered, which indicates the relative proportion of investor's equity and debt used to finance the cost of investment. The cost of debt $\left(K_{d}\right)$ is composed of the rate of interest paid and can be modelled as the risk-free plus a risk component which incorporate a probable rate of default. In our model, the $K_{d}$ is set at $3.75 \%$ as average of the $K_{d}$ suggested for the Euro zone according to Bloomberg and Deloitte [13].

The cost of equity $\left(K_{e}\right)$ is the sum of the risk-free rate and the equity premium. We can obtain the $K_{e}$ by using the capital asset pricing model, which says that the investor requires a minimum rate of return equal to the return from a risk-free investment plus a return for bearing extra risk. This extra risk is called the "equity risk premium" and is equivalent to the risk premium of the market times a multiplier called beta, which expresses the sensitivity of a share to market variations; $K_{e}$ is assumed at $10.55 \%$ again as average of data coming from the market.

All the data introduced in the model are reflecting prices, costs and rates of 2014. However, the model can be applied by simply updating the inputs to new values, or, in the case of its application in other national contexts, using the economic values proper of that country. 
The DCFA has been then integrated with external costs in order to obtain a simple cost benefit analysis (CBA). CBA is not limited to monetary considerations only but it often includes environmental and social costs/benefits that can be quantified with a direct or indirect method. In our case study, the CBA attaches monetary value to carbon dioxide emissions reductions and brings it into energy-related investment decisions. The external costs that arise from the environmental impact of energy production are included in the discounted cash flow model, and they reflect the climate change damage costs associated with emissions of carbon dioxide $\left(\mathrm{CO}_{2}\right)$ or, on the other way, they incorporate the social benefits of reducing emissions of $\mathrm{CO}_{2}$ into cost-benefit analysis.

Climatic changes are likely to generate economic and social costs, but it is usually difficult to give a monetary value to one tonne of $\mathrm{CO}_{2}$. Two different approaches are used: the first is called social cost of carbon (SCC), which is an estimated of the monetised global damages associated with an incremental increase in carbon emission (changes in agricultural productivity and in value of ecosystem services, human health, property damages, etc.). The SCC is estimated as the net present value of the long-term climate change impacts of one additional tonne of carbon emitted today.

The second approach is called marginal abatement cost (MAC) and represents the cost of abating the next unit of emissions for a given target level. Abatement includes reductions in economic activity, switching fuel sources, altering production processes, and sequestering carbon in the soil, trees, or ground. The MAC is usually presented as a series of costs on a curve, showing how the cost increases for each additional unit of emission reduction. MAC curves can be derived in different ways (via consultation with experts or by using an energy model).

In the European Union, a MAC approach has been used as it is reflected in the European Union emissions trading system (EU ETS). Nevertheless, different values have been included in cost benefit analysis, which are different from the current price in the EU ETS of around $7 € / \mathrm{t} \mathrm{CO}_{2^{-}}$ eq at current exchange rate. In our analysis a carbon price of around $40 € /$ tonne $\mathrm{CO}_{2}$ has been used as a weighted average of the MAC and SCC values. The price is precautionary and it represents a mean of what is suggested in European policy seeking to implement the most economically efficient climate change mitigation. The production of $\mathrm{CO}_{2}$ with a GCHP system and with a $\mathrm{CB}$ system are compared and their values are included in a different set of simulations, that we called CBA.

The carbon footprint for electricity production and natural gas production have been calculate. The carbon footprint for different scenarios are represented in Tab.6, and in Fig.7 the regression analysis shows how the carbon footprint for electricity production have been intended, considering data from [14]. Both the DCFA and the CBA have been performed within a period of 15 years.

\section{Results and discussion}

As introduced in [2], we assume that the ratio between the cost of the electricity and the natural gas (EMR, energy mix ratio) may express the Nation energetic strategy, with regard of the direct exploitation of a primary energy like the natural gas and the overall resources employed in electricity production. In Fig. 6 are showed the EMRs given by natural gas price for EU28 and other European countries, whereas in Fig.7 is reported the relationship between the EMR ratio and the carbon footprint of the electricity production, with regard only to the major European countries.

Therefore, four scenarios $(1 / 2 / 3 / 4)$ where tested in order to consider different EMR ratios, selected to represent the extreme values of the EU28 and its average. 


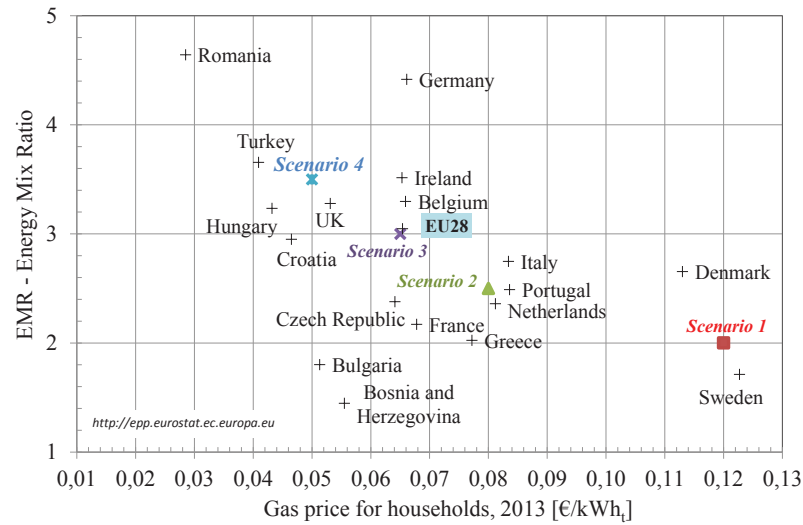

Figure 6: EMR for EU Countries

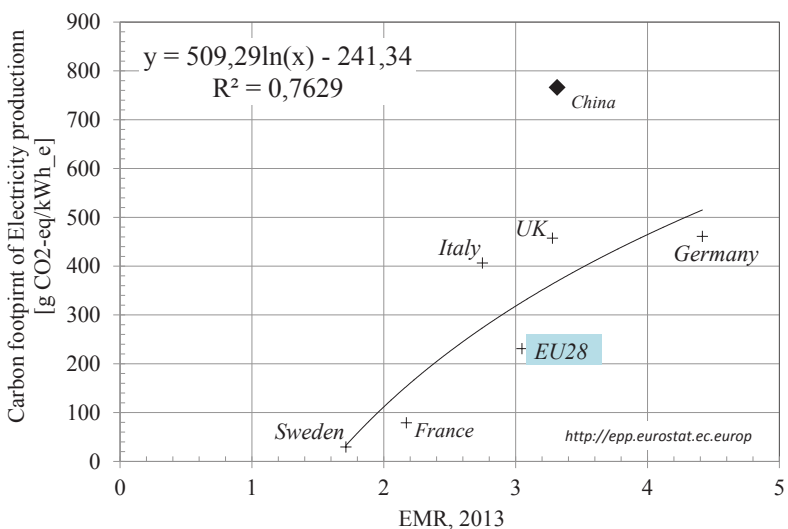

Figure 7: Carbon Footprint for Electricity production

From Tab.7 to Tab.10, the major results of the energetic analysis are reported for cubic meter of building. The results show that in climate zone $B$, the cooling mode outnumbers the heating mode, and thus the resulting length of the GHE is controlled by the cooling season, such as the maximum power of air-conditioning plant. Moreover, unlike each other climate zones, the $F$ zone does not need requirement in cooling mode, and thus it avoids this function in the air-conditioning plant. Tab.11 and Tab.12 report the electricity and gas consumption of the seasonal heating period per cubic metre of building. Assuming an overall simplified conversion factor of $5 \mathrm{kWh}_{\mathrm{e}} / \mathrm{Nm}^{3}$ between the natural gas and the electricity, the GCHP saving in terms of primary energy is well evident and higher than the $50 \%$ in comparison with the $\mathrm{CB}$.

From Tab.13 to Tab.20, the different payback periods are presented for both DCFA and for the CBA, which was performed introducing the carbon price and the carbon footprint for electricity and natural gas. The payback periods are exhibited for different scenarios $(1 / 2 / 3 / 4)$, with a predetermined period of 15 years chosen as number of years over which it was thinkable to value project profitability. If we consider the $a$ and $b$ energy labels, in all scenario we see that they show a suitable payback period for an householder, not matter which EMR was used or which gas prices. Conversely, with the $f$ label all the solutions overcame the period used for the analysis (indicated with $n c$ ). The $c$ label is a good opportunity for the GCHP technology only in certain climate zone as $b, c$ and $d$. When we change the EMR from 0.286 to 0.333 and the gas price from 0.683 to 0.525 $€ / \mathrm{Nm}^{3}$, we see that almost all the solutions won't give a positive results, with longer payback periods, which means that they do not perform in terms of recovering the initial cost of investment. The BCA shows that the introduction of carbon price in the model, and the following computation and monetization of emission savings, the payback periods do not improve and they change only in certain combination of energy labels and climate zones ( $e$ and $f$ ). The relatively modest carbon price has a very little economic impact in the comparison of the GCHP over the CB. 
Table 7: Maximum power in heating, $W_{\mathrm{t}} / \mathrm{m}^{3}$

\begin{tabular}{c|ccccc}
\cline { 2 - 6 } & $B$ & $C$ & $D$ & $E$ & $F$ \\
\hline$a$ & 3.5 & 5.1 & 6.1 & 7.8 & 6.5 \\
$b$ & 6.3 & 9.2 & 10.9 & 13.7 & 11.5 \\
$c$ & 9.3 & 13.3 & 15.8 & 19.8 & 16.3 \\
$d$ & 12.5 & 17.9 & 21.1 & 26.4 & 21.6 \\
$e$ & 17.5 & 25.0 & 29.5 & 36.6 & 29.8 \\
$f$ & 26.8 & 38.3 & 44.9 & 55.5 & 44.5 \\
\hline
\end{tabular}

Table 9: GHE length in heating, $\mathrm{m} / \mathrm{m}^{3}$

\begin{tabular}{c|ccccc}
\cline { 2 - 6 } & $B$ & $C$ & $D$ & $E$ & $F$ \\
\hline$a$ & 0.096 & 0.138 & 0.167 & 0.210 & 0.177 \\
$b$ & 0.172 & 0.249 & 0.295 & 0.372 & 0.311 \\
$c$ & 0.252 & 0.362 & 0.430 & 0.537 & 0.443 \\
$d$ & 0.338 & 0.485 & 0.573 & 0.716 & 0.586 \\
$e$ & 0.474 & 0.678 & 0.800 & 0.993 & 0.807 \\
$f$ & 0.727 & 1.038 & 1.216 & 1.505 & 1.207 \\
\hline
\end{tabular}

Table 11: Electricity consumption, $k W h_{\mathrm{e}} / \mathrm{m}^{3}$ year

\begin{tabular}{c|ccccc}
\cline { 2 - 6 } & $B$ & $C$ & $D$ & $E$ & $F$ \\
\hline$a$ & 0.552 & 0.834 & 1.285 & 1.647 & 1.884 \\
$b$ & 0.949 & 1.442 & 2.194 & 2.825 & 3.230 \\
$c$ & 1.342 & 2.030 & 3.098 & 3.964 & 4.503 \\
$d$ & 1.742 & 2.641 & 4.016 & 5.148 & 5.833 \\
$e$ & 2.343 & 3.552 & 5.397 & 6.908 & 7.807 \\
$f$ & 3.396 & 5.146 & 7.784 & 9.959 & 11.182 \\
\hline
\end{tabular}

Table 13: Payback period (scenario 1)

\begin{tabular}{c|ccccc}
\cline { 2 - 6 } & $B$ & $C$ & $D$ & $E$ & $F$ \\
\hline$a$ & $<1$ & $<1$ & $<1$ & 1 & 6 \\
$b$ & 2 & 2 & 3 & 5 & 8 \\
$c$ & 7 & 5 & 6 & 8 & 9 \\
$d$ & 9 & 8 & 8 & 9 & 10 \\
$e$ & 10 & 9 & 10 & 12 & 8 \\
$f$ & $n c$ & 11 & 12 & $n c$ & 11 \\
\hline
\end{tabular}

Table 8: Maximum power in cooling, $W_{t} / \mathbf{m}^{3}$

\begin{tabular}{l|rrrrr}
\cline { 2 - 6 } & \multicolumn{1}{c}{$B$} & $C$ & \multicolumn{1}{l}{$D$} & \multicolumn{1}{l}{$E$} \\
\hline$a$ & -5.2 & -4.5 & -3.5 & -2.7 & 0.0 \\
$b$ & -9.0 & -7.7 & -6.0 & -4.7 & 0.0 \\
$c$ & -13.2 & -11.0 & -8.4 & -6.4 & 0.0 \\
$d$ & -17.9 & -14.8 & -10.8 & -8.4 & 0.0 \\
$e$ & -25.2 & -20.9 & -15.0 & -10.9 & -0.8 \\
$f$ & -39.1 & -32.3 & -23.2 & -15.9 & -4.9 \\
\hline
\end{tabular}

Table 10: GHE length in cooling, $\mathrm{m} / \mathrm{m}^{3}$

\begin{tabular}{c|ccccc}
\cline { 2 - 6 } & $B$ & $C$ & $D$ & $E$ & $F$ \\
\hline$a$ & 0.067 & 0.122 & 0.096 & 0.074 & 0.000 \\
$b$ & 0.243 & 0.209 & 0.163 & 0.126 & 0.000 \\
$c$ & 0.359 & 0.298 & 0.228 & 0.174 & 0.000 \\
$d$ & 0.485 & 0.403 & 0.293 & 0.227 & 0.000 \\
$e$ & 0.685 & 0.567 & 0.407 & 0.296 & 0.023 \\
$f$ & 1.059 & 0.876 & 0.628 & 0.431 & 0.134 \\
\hline
\end{tabular}

Table 12: Natural gas consumption, $\mathrm{Nm}^{3} / \mathrm{m}^{3}$ year

\begin{tabular}{c|ccccc}
\cline { 2 - 6 } & $B$ & $C$ & $D$ & $E$ & $F$ \\
\hline$a$ & 0.305 & 0.455 & 0.687 & 0.858 & 0.946 \\
$b$ & 0.524 & 0.788 & 1.174 & 1.473 & 1.622 \\
$c$ & 0.742 & 1.111 & 1.658 & 2.067 & 2.262 \\
$d$ & 0.964 & 1.446 & 2.150 & 2.686 & 2.931 \\
$e$ & 1.298 & 1.947 & 2.892 & 3.606 & 3.923 \\
$f$ & 1.883 & 2.824 & 4.174 & 5.202 & 5.621 \\
\hline
\end{tabular}

Table 14: Payback period of CBA (scenario 1)

\begin{tabular}{c|ccccc}
\cline { 2 - 6 } & $B$ & $C$ & $D$ & $E$ & $F$ \\
\hline$a$ & $<1$ & $<1$ & $<1$ & 1 & 6 \\
$b$ & 2 & 2 & 3 & 5 & 7 \\
$c$ & 6 & 5 & 5 & 7 & 8 \\
$d$ & 8 & 7 & 7 & 8 & 9 \\
$e$ & 10 & 8 & 9 & 11 & 7 \\
$f$ & 14 & 10 & 11 & 13 & 9 \\
\hline
\end{tabular}


Table 15: Payback period (scenario 2)

\begin{tabular}{c|ccccc}
\cline { 2 - 6 } & $B$ & $C$ & $D$ & $E$ & $F$ \\
\hline$a$ & $<1$ & $<1$ & $<1$ & 1 & 8 \\
$b$ & 3 & 3 & 4 & 7 & 12 \\
$c$ & 9 & 8 & 9 & 12 & $n c$ \\
$d$ & 12 & 11 & 13 & $n c$ & $n c$ \\
$e$ & $n c$ & 13 & $n c$ & $n c$ & $n c$ \\
$f$ & $n c$ & $n c$ & $n c$ & $n c$ & $n c$ \\
\hline
\end{tabular}

Table 18: Payback period (scenario 3)

\begin{tabular}{c|ccccc}
\cline { 2 - 6 } & $B$ & $C$ & $D$ & $E$ & $F$ \\
\hline$a$ & $<1$ & $<1$ & $<1$ & 1 & 10 \\
$b$ & 3 & 3 & 5 & 9 & $n c$ \\
$c$ & 11 & 9 & 11 & $n c$ & $n c$ \\
$d$ & $n c$ & $n c$ & $n c$ & $n c$ & $n c$ \\
$e$ & $n c$ & $n c$ & $n c$ & $n c$ & $n c$ \\
$f$ & $n c$ & $n c$ & $n c$ & $n c$ & $n c$ \\
\hline
\end{tabular}

Table 19: Payback period (scenario 4)

\begin{tabular}{c|ccccc}
\cline { 2 - 6 } & $B$ & $C$ & $D$ & $E$ & $F$ \\
\hline$a$ & $<1$ & $<1$ & $<1$ & 1 & 12 \\
$b$ & 4 & 5 & 6 & 11 & $n c$ \\
$c$ & 13 & 11 & $n c$ & $n c$ & $n c$ \\
$d$ & $n c$ & $n c$ & $n c$ & $n c$ & $n c$ \\
$e$ & $n c$ & $n c$ & $n c$ & $n c$ & $n c$ \\
$f$ & $n c$ & $n c$ & $n c$ & $n c$ & $n c$ \\
\hline
\end{tabular}

\section{Conclusions} value to carbon dioxide emissions reductions.
Table 16: Payback period of CBA (scenario 2)

\begin{tabular}{c|ccccc}
\cline { 2 - 6 } & $B$ & $C$ & $D$ & $E$ & $F$ \\
\hline$a$ & $<1$ & $<1$ & $<1$ & 1 & 8 \\
$b$ & 3 & 3 & 4 & 6 & 11 \\
$c$ & 8 & 7 & 8 & 10 & 13 \\
$d$ & 11 & 10 & 11 & 13 & $n c$ \\
$e$ & 14 & 12 & 14 & $n c$ & $n c$ \\
$f$ & $n c$ & $n c$ & $n c$ & $n c$ & $n c$ \\
\hline
\end{tabular}

Table 17: Payback period of CBA (scenario 3)

\begin{tabular}{c|ccccc}
\cline { 2 - 6 } & $B$ & $C$ & $D$ & $E$ & $F$ \\
\hline$a$ & $<1$ & $<1$ & $<1$ & 1 & 9 \\
$b$ & 3 & 3 & 5 & 8 & 14 \\
$c$ & 10 & 8 & 10 & 14 & $n c$ \\
$d$ & 13 & 13 & $n c$ & $n c$ & $n c$ \\
$e$ & $n c$ & $n c$ & $n c$ & $n c$ & $n c$ \\
$f$ & $n c$ & $n c$ & $n c$ & $n c$ & $n c$ \\
\hline
\end{tabular}

Table 20: Payback period of CBA (scenario 4)

\begin{tabular}{c|ccccc}
\cline { 2 - 6 } & $B$ & $C$ & $D$ & $E$ & $F$ \\
\hline$a$ & $<1$ & $<1$ & $<1$ & 1 & 11 \\
$b$ & 4 & 4 & 6 & 10 & $n c$ \\
$c$ & 11 & 10 & 13 & $n c$ & $n c$ \\
$d$ & $n c$ & $n c$ & $n c$ & $n c$ & $n c$ \\
$e$ & $n c$ & $n c$ & $n c$ & $n c$ & $n c$ \\
$f$ & $n c$ & $n c$ & $n c$ & $n c$ & $n c$ \\
\hline
\end{tabular}

In this paper we evaluate the PBPs for a ground-coupled heat pump (GCHP) in comparison with a condensing boiler (CB), in connection with degree-days, energy building labels and an energy mix ratio (EMR), which reflects the ratio between electricity and gas price. A numerical model was used to value the soil temperature modified from the GHE, and this solution was scaled to approach the other combinations among climate zones and energy labels. The economic analysis was performed through a DCFA and, at a later time, with a CBA introducing the

The thermo-physical behaviour of a generic building has been parameterized with regard of an overall equivalent transmittance coefficient, and of the climate zones. The first one has been related to the energy labels, and the second to the heating degree-days. As consequence, the energy requirement, the maximum heating/cooling power and other detail of the air-condition plant have been quantified. The sizing of the GHE has been parameterized too, taken into account a benchmark case, which was solved by means of a numerical model in a former analysis. 
The numerical analysis has taken into account the GHE behavior during summer, but the economic approach has considered only the installation extra-cost in the CB case and not the energy consumptions, as they are very similar in the two cases considered.

Finally, the results have supported the economic analysis. The PBP was calculated for different scenarios (1/2/3/4), in combination with different energy labels and climate zone. The analysis aims at showing if the PBPs were smaller than some pre-determined number of years (15 years) and so the investment of GCHP was worth undertaking. The models show different results. In some case, with a favourable energy label of $a$ and $b$, and in all scenarios considered, the investor/householder could recoup the greater cost of installing a GCHP rather than a CB. On the other hand, with the $e$ and $f$ label almost all the solutions overcame the period used for the analysis. Only in the first scenario, which represents the case of a higher cost for natural gas, the $e$ and $f$ label show good PBP.

The use of the carbon price in the analysis that was performed with a CBA approach shows that the PBP does not improve the economic performance of the GCHP. In very few cases, as climate zone e and $\mathrm{f}$, the monetization of emission savings displays some shorter PBPs. The modest carbon price has a very little economic impact in the comparison of the GCHP over the CB. In future applications a sensitivity analysis could be implemented in the model, using a stochastic approach, in order to include the uncertainty, which lies in the assessment of the inputs involved in the DCFA and CBA models.

\section{REFERENCES}

[1] B. Kulcar, D. Goricanec, J. Krope, Economy of exploiting heat from low-temperature geothermal sources using a heat pump, Energy and Buildings, 2008, 40, 323-329.

[2] M. Bottarelli and L. Gabrielli, Payback period for a ground source heat pump system, Int. J. of Heat \& Technology, 2011, 29(2), 145-150.

[3] M. Bottarelli and V. Di Federico, Adoption of flat panels in soil heat exchange, Proceedings of 11th World Renewable Energy Congress, Abu Dhabi, 2010, 330-335.

[4] M. Bottarelli and V. Di Federico, Numerical comparison between two advanced HGHEs, Int. J. of Low-Carbon Technologies, 2012, 6(2), 75-81.

[5] D.P. Wilson and R.S. Basu, Thermodynamic properties of a new stratospherically safe working fluid - Refrigerant R134a, ASHRAE Transactions, 1988, 94.

[6] DHI-WASY GmbH, OpenLoop IFM Module, 2009.

[7] N. French, L. Gabrielli, Discounted cash flow: accounting for uncertainty, Journal of Property Investment and Finance, 2005, 23, 1, 76-89.

[8] N. French, L. Gabrielli, Uncertainty and feasibility Studies: an Italian case study, Journal of Property Investment and Finance, 2005, 24, 1, 49-67.

[9] G. Brown, G. Matysiak, Real Estate Investment, Prentice Hall, 2000.

[10] Y. Zhu, Y. Tao, R. Rayegan, A comparison of deterministic and probabilistic life cycle cost analyses of ground source heat pump (GSHP) applications in hot and humid climate, Energy and Buildings, 2012, 55, 312-321.

[11] Eurostat, http://epp.eurostat.ec.europa.eu. 
[12] C Kulcar B., Goricanec D. Krope J. Economy of exploiting heat from low-temperature geothermal sources using a heat pump, Energy and buildings, 40, 2008, pp. $323-329$.

[14] E IEA, CO2 Emissions from fuel combustion - Highlights, 2012. 